\title{
KAJIAN PEMANFAATAN REVERSE FLOW REACTOR UNTUK OKSIDASI KATALITIK UAP BENSIN
}

\author{
Profiyanti Hermien Suharti ${ }^{1}$, Yogi Wibisono Budhi2 ${ }^{*}$, dan Yazid Bindar ${ }^{2}$ \\ 1) Jurusan Teknik Kimia, Politeknik Negeri Malang, Kampus I POLINEMA \\ Jalan Veteran 8, PO BOX 04, Malang 65145 \\ 2)Program Studi Teknik Kimia, Fakultas Teknologi Industri, ITB \\ Jalan Ganesha 10 Bandung 40132 \\ email: Y.Wibisono@che.itb.ac.id
}

\begin{abstract}
Abstrak
Oksidasi katalitik uap bensin adalah salah satu cara untuk mengurangi emisi uap bensin di stasiun pengisian bahan bakar umum. Reaksi ini adalah reaksi eksotermik, sehingga panas reaksi yang timbul dapat dimanfaatkan untuk memanaskan umpan agar reaktor dapat berperilaku ototermal. Kondisi ototermal dengan umpan emisi uap bensin yang berkonsentrasi rendah dapat tercapai dengan menggunakan reverse flow reactor (RFR), yaitu reaktor unggun tetap yang arah alirannya diubah secara periodik. Tujuan kajian ini adalah untuk mengkaji pemanfaatan RFR untuk menurunkan emisi uap bensin di SPBU, berdasarkan simulasi menggunakan FlexPDE versi 6 dan nantinya digunakan sebagai dasar pengembangan secara eksperimental. Model RFR dikembangkan dengan menggunakan isooktana sebagai komponen model. Simulasi terdiri dari (1) simulasi RFR satu arah, yang digunakan sebagai dasar penentuan kondisi operasi RFR dan (2) simulasi RFR dengan konfigurasi start-up tertentu. Parameter kinetika dan sifat-sifat fisik yang diperlukan diambil dari literatur. Hasil simulasi RFR satu arah menunjukkan bahwa reaksi oksidasi katalitik uap bensin dapat terselenggara dengan baik pada suhu $773 \mathrm{~K}$, sedangkan simulasi RFR kondisi aliran bolak-balik menunjukkan adanya akumulasi panas di unggun reaktor yang dapat dimanfaatkan saat proses start-up. Waktu untuk mencapai konversi $100 \%$ untuk simulasi mode operasi bolak-balik lebih cepat daripada mode operasi satu arah. Dengan demikian penyelenggaraan reaksi oksidasi katalitik emis uap bensin di reverse flow reactor secara eksperimental dapat dikembangkan.
\end{abstract}

Kata Kunci: Reaktor dinamik, Oksidasi katalitik

\begin{abstract}
Catalytic oxidation of gasoline vapor is one of methods to reduce the gasoline vapor emission at fuel station. This reaction is exothermic with large heat of reaction, so that the heat released can be used for heating the feed gas, leading to auto thermal condition.. The auto thermal conditions with low feed concentration, like gasoline vapor emission, can be achieved by using a reverse-flow reactor (RFR), a kind of fixed bed reactor in which flow direction is periodically changed. The objective of this research is to develop the using of a RFR to reduce the gasoline vapor emissions at fuel station, based on simulations using FlexPDE version 6 and later used as the basis for the experimental development. The model of RFR was developed, by using iso-octane as a model component. The simulation consists of: (1) RFR with one way direction, which was used as the basis for the determination of RFR operating conditions and (2) RFR at current start-up conditions. The simulations were conducted using a software package FlexPDE version 6 . The kinetic parameters and physical properties were taken from literature. The simulation results of the RFR at one way direction show that catalytic oxidation of gasoline vapor can conducted best at temperature of $773 \mathrm{~K}$, while the RFR shows the accumulation of heat in the reactor bed that can be utilized for process start-up. Time to reach $100 \%$ conversion of gasoline for reverse flow operation mode is faster than one way operation mode. Thus the operation of gasoline emission catalytic oxidation reaction in reverse flow reactor can be developed experimentally.
\end{abstract}

Keywords: Dynamic reactor, Catalytic oxidation

*korespondensi 


\section{Pendahuluan}

Bensin dapat dikategorikan sebagai komponen organik yang mudah menguap atau volatile organic compound (VOC), karena sebagian besar komponen bensin memiliki tekanan uap yang cukup tinggi pada kondisi atmosferik sehingga dapat menguap dengan mudah. Penguapan ini dapat menyebabkan kerugian ekonomi maupun bahaya bagi lingkungan di sekitar SPBU, termasuk orang-orang yang berada di lokasi tersebut [Chameides dkk., 1999]. Tabel 1 menunjukkan nilai kerugian ekonomi akibat penguapan BBM setiap tahunnya.

Selain kerugian ekonomi, penguapan bensin di SPBU juga menyebabkan adanya polusi udara dan dapat membahayakan kesehatan manusia karena emisi uap bensin untuk jangka waktu yang panjang dapat menyebabkan iritasi saluran pernafasan, paru-paru basah (pulmonary edema), dan kecanduan. Kondisi ini diperparah oleh kenyataan bahwa uap bensin mempunyai massa jenis yang lebih besar daripada udara (3-4 kali lipat) dan waktu tinggal di udara (atmospheric lifetime) cukup besar, yaitu lebih dari 27,5 jam. Hal ini menyebabkan uap bensin mayoritas akan selalu berada di sekitar SPBU untuk jangka waktu yang panjang [Allen dkk., 2002].

Faktor kerugian ekonomi dan kesehatan tersebut mendorong dikembangkannya teknologi untuk mengurangi emisi uap bensin di SPBU. Salah satu teknologi yang banyak digunakan adalah pemakaian sistem vapor recovery, baik yang menggunakan prinsip adsorpsi, kondensasi, maupun membran [Erwin, 2007].

Pemakaian sistem vapor recovery masih menyisakan uap bensin di udara sekitar SPBU meskipun dengan konsentrasi rendah, Konsentrasi uap bensin yang rendah dan bervariasi terhadap waktu membutuhkan penanganan khusus. Reaktor yang dapat mengakomodasi kondisi tersebut adalah reaktor yang beroperasi secara dinamik. Dalam mode operasi ini, reaktor sengaja dipertahankan dalam kondisi dinamik. Kondisi dinamik dapat diperoleh dengan cara modulasi komposisi atau pembalikan arah aliran [Reshetnikov dkk., 2003].

Salah satu jenis reaktor dinamik yang banyak dikembangkan untuk mengolah VOC adalah reverse flow reactor (RFR). RFR adalah reaktor unggun diam dengan arah aliran yang diubah secara periodik. RFR dapat meningkatkan konversi reaksi, memperbaiki distribusi produk, dan menurunkan kebutuhan energi. Unggun yang terdapat di dalam RFR, berupa katalis dan inert, dapat berfungsi sebagai penyimpan Jika reaksi yang berlangsung adalah reaksi eksotermik, seperti reaksi pembakaran, maka panas yang dihasilkan dapat disimpan di dalam unggun reaktor [Silveston dkk., 1995].

Reaksi pembakaran uap bensin adalah salah satu reaksi yang sangat eksotermis, sehingga dalam kajian ini dipelajari kemampuan RFR untuk mengurangi uap bensin melalui reaksi pembakaran, khususnya reaksi pembakaran berkatalis, yang lebih dikenal dengan istilah reaksi oksidasi katalitik. Kinerja RFR dievaluasi berdasarkan kinerja reaktor unggun tetap (fixed bed reactor - FBR) yang beroperasi satu arah.

\section{Dasar Teori \\ Penanganan Uap Bensin di SPBU}

Penguapan bensin di SPBU terjadi pada saat proses pengisian bahan bakar dari truk pengirim ke dalam tangki penampung SPBU (dikenal dengan istilah proses unloading), maupun pada saat proses pengisian bahan bakar dari tangki penampung menuju ke kendaraan bermotor

Tabel 1. Kerugian akibat penguapan BBM

\begin{tabular}{|c|c|c|c|c|}
\hline Jenis BBM & $\begin{array}{c}\text { Konsumsi Nasional Rata- } \\
\text { Rata Tahun } 2008^{1} \\
\text { (Liter/bulan) }\end{array}$ & $\begin{array}{c}\text { Faktor rugi }{ }^{1} \\
(\%)\end{array}$ & $\begin{array}{l}\text { Harga } B^{-} M^{2} \\
(\mathrm{Rp} / \mathrm{L})\end{array}$ & $\begin{array}{l}\text { Kerugian Ekonomi } \\
\text { (Rp/bulan) }\end{array}$ \\
\hline Bensin & 1.348 .105 .000 & 0,78 & 4500 & 47.318 .488 .425 \\
\hline Solar & 986.341 .000 & 0,10 & 4500 & 4.438 .538 \\
\hline \multicolumn{4}{|c|}{ JUMLAH } & 47.322 .926 .963 \\
\hline
\end{tabular}


(proses loading). Penguapan pada proses unloading tidak terlalu besar, yaitu sebesar $11 \%$ dari total penguapan bensin yang terjadi di SPBU, karena proses unloading hanya terjadi maksimal satu kali dalam sehari. Sedang proses loading memberikan kontribusi sebesar $89 \%$ dari total penguapan bensin yang terjadi di SPBU, karena tingginya frekuensi pengisian bahan bakar di SPBU [Erwin, 2007].

Permasalahan uap bensin yang terjadi pada saat proses unloading maupun pada saat proses loading diselesaikan dengan pemasangan vapor recovery unit (VRU). Teknologi VRU yang telah dikembangkan terdiri dari empat macam yaitu: (1) absorpsi dengan menggunakan pelarut, (2) absorpsi dengan menggunakan karbon aktif, (3) kondensasi uap bensin, dan (4) pemisahan dengan membran [Erwin, 2007]. Penggunaan VRU masih menyisakan sebagian kecil uap bensin di sekitar SPBU. Mengingat besarnya bahaya uap bensin maka teknologi untuk mengolah uap bensin yang masih tersisa, dengan menggunakan RFR, akan dicoba dikembangkan.

\section{Reaktor dinamik}

Perubahan mode operasi satu arah (one way operation) pada pengoperasian reaktor unggun tetap menjadi mode operasi dinamik banyak didiskusikan dalam berbagai literatur sejak tahun 1960. Reaktor unggun tetap dioperasikan dalam kondisi dinamik secara sengaja untuk meningkatkan kinerja reaktor. Pada kasus-kasus tertentu, distribusi produk yang dihasilkan reaktor dinamik dapat lebih baik daripada kondisi operasi satu arah [Silveston, 1998].

Reaktor dinamik adalah reaktor yang sengaja dioperasikan dalam kondisi dinamik, sehingga memiliki variabel proses yang berubah terhadap waktu. Perubahan variabel proses pada reaktor unggun tetap dapat menyebabkan perubahan konsentrasi di permukaan aktif katalis dan mempengaruhi kecepatan reaksi pada reaksi berkatalis. Konsep ini banyak digunakan untuk meningkatkan kinerja reaktor, khususnya dalam hal konversi atau selektivitas produk [Silveston dkk., 1995].

Kondisi dinamik dapat diperoleh dengan cara memberikan gangguan secara sengaja terhadap setiap variabel proses. Beberapa teknik aplikasi gangguan yang banyak digunakan untuk meningkatkan kinerja reaktor berkatalis adalah (1) modulasi parameter operasi reaktor secara periodik, (2) penambahan sejumlah kecil reaktan ke dalam aliran umpan masuk reaktor secara periodik, dan (3) mengubah arah aliran umpan masuk ke dalam reaktor secara periodik [Budhi, 2005]

Perubahan arah aliran umpan masuk ke dalam reaktor secara periodik lebih dikenal dengan istilah RFR. Cara ini memberikan keuntungan jika diaplikasikan pada reaksi yang sangat eksotermis, terutama dalam hal teknik penyimpanan energi. Umpan dengan temperatur yang rendah dapat direaksikan pada temperatur yang tinggi, tanpa membutuhkan pemanasan awal (preheater) [Matros \& Bunimovich, 1996]. Aplikasi RFR relatif lebih mudah daripada kedua teknik yang lain sehingga pemanfaatannya di dunia industri semakin meningkat.

\section{Reverse flow reactor}

Reverse flow reactor (RFR) didefinisikan sebagai reaktor unggun tetap yang arah alirannya diubah secara periodik dalam selang waktu tertentu yang disebut switching time. Gambar 1 menunjukkan skema pengoperasian reaktor unggun tetap satu arah (Gambar 1(a)) dan dalam kondisi dinamik / RFR (Gambar 1 (b)).

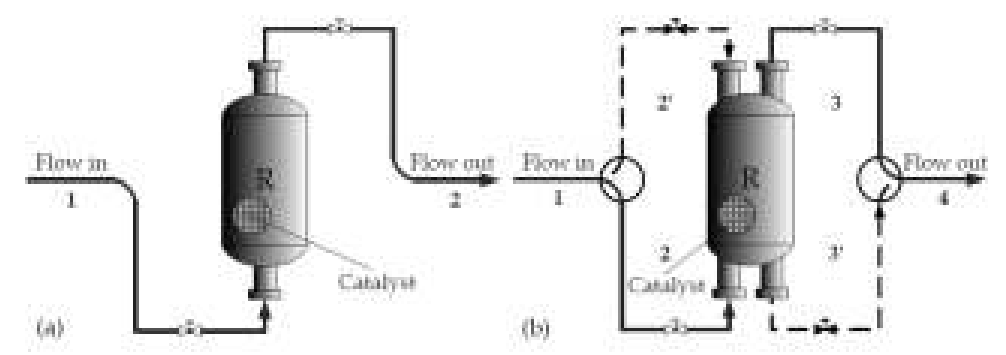

Gambar 1. Skema reaktor unggun tetap: (a) dalam kondisi operasi satu arah; dan (b) reverse flow reactor (RFR) [Budhi, 2005]. 
Jika dioperasikan secara tunak, maka aliran proses adalah 1-R-II. Sedang untuk RFR, proses terdiri dari dua siklus. Pada siklus pertama, umpan mengalir ke dalam reaktor melalui urutan 1-2-R-3-4, dan pada siklus berikutnya umpan mengalir melalui urutan 1-2'-R-3'-4 [Budhi, 2005].

Kajian tentang pemakaian RFR untuk oksidasi VOC telah diaplikasikan di dunia industri, terutama di Eropa Barat, karena beberapa alasan, yaitu: (1) oksidasi katalitik berlangsung pada temperatur yang jauh lebih rendah daripada pembakaran fasa homogen, dan mampu menghilangkan sebagian besar VOC yang terkandung tanpa adanya pembentukan $\mathrm{NO}_{\mathrm{x}}$ [Matros \& Bunimovich, 1996], (2) proses oksidasi katalitik dengan menggunakan RFR memiliki kemampuan untuk beroperasi secara ototermal (tanpa membutuhkan media pemanas), walaupun $\Delta T_{a d}$ komponen yang dihilangkan cukup kecil $\left(20-30{ }^{\circ} \mathrm{C}\right)$ [Barresi dkk., 2007], dan (3) proses oksidasi katalitik konvensional memiliki keterbatasan dalam memurnikan udara dengan laju alir dan konsentrasi yang bervariasi. Hal ini terjadi karena perubahan konsentrasi maupun laju alir dapat menyebabkan perubahan $\Delta T_{a d}$ yang dihasilkan selama proses berlangsung. Jika $\Delta T_{a d}$ berkurang, maka kemampuan sistem untuk beroperasi secara ototermal juga berkurang dan akan membutuhkan pemanas [Matros \& Bunimovich, 1996].

\section{Metodologi}

Penelitian mengenai aplikasi reverse flow reactor (RFR) untuk mengolah uap bensin diawali dengan membangun persamaan model untuk RFR berdasarkan persamaan neraca massa pseudohomogeneous dan neraca energi heterogen satu dimensi di reaktor unggun tetap serta batasan-batasan kriteria rancangan untuk reaktor unggun tetap. Model tersebut disimulasikan menggunakan perangkat lunak FlexPDE versi 6.0 (PDE Solutions Inc., 2009), untuk beberapa variabel operasi.

Simulasi bertujuan untuk mengetahui kinerja RFR dalam mengkonversikan uap bensin menjadi $\mathrm{CO}_{2}$, sehingga prosentase pengurangan uap bensin di SPBU dapat diketahui. Kinerja RFR dibandingkan dengan kinerja FBR yang beroperasi satu arah. Hasil simulasi dianalisis lebih lanjut, sehingga diperoleh metoda pengoperasian RFR untuk reaksi oksidasi katalitik uap bensin yang tepat. Hasil simulasi ini digunakan sebagai dasar untuk pengembangan kondisi operasi RFR untuk oksidasi katalitik uap bensin secara eksperimental.

\section{Pemodelan}

RFR, tempat berlangsungnya reaksi oksidasi uap bensin, dimodelkan sebagai reaktor unggun tetap dengan 3 zona yaitu: zona inert, zona katalis, dan zona inert, seperti terlihat pada Gambar 2. Reaksi oksidasi uap bensin hanya terjadi di zona katalis. Panjang zona inert disimbolkan dengan notasi $\mathrm{z}_{\mathrm{i}}$, sedangkan panjang zona katalis disimbolkan dengan notasi $z_{r}$, sehingga w menunjukkan panjang zona inert dan zona kataslis $\left(\mathrm{z}_{\mathrm{i}}+\mathrm{z}_{\mathrm{r}}\right)$, dan $\mathrm{L}_{\mathrm{r}}$ menujukkan panjang total reaktor $\left(2 \cdot z_{i}+z_{r}\right)$.

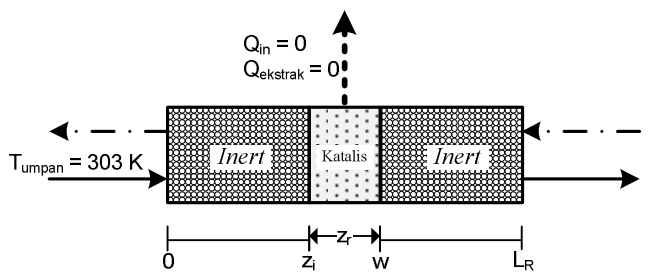

\section{Gambar 2. Konfigurasi reaktor untuk simulasi RFR}

Uap bensin yang mengandung banyak komponen VOC dimodelkan hanya mengandung iso-oktana. Iso-oktana dipilih sebagai komponen model dengan beberapa alasan, yaitu (1) merupakan hidrokarbon alifatis rantai panjang yang jarang dikaji dalam reaksi oksidasi katalitik, (2) banyak digunakan sebagai komponen model dalam kajian yang melibatkan motor bakar (internal combustion engines), dan (3) ketersediaan data kinetika reaksi oksidasi [10]. Reaksi oksidasi uap bensin di RFR dinyatakan dalam persamaan [1].

$\mathrm{C}_{8} \mathrm{H}_{18}+12,5 \mathrm{O}_{2} \rightarrow 8 \mathrm{CO}_{2}+9 \mathrm{H}_{2} \mathrm{O}$

Model persamaan yang menyatakan laju reaksi di atas diperoleh dari kajian Petrachi dkk. (2005), yang menyebutkan bahwa

$r_{A}=k_{1} p_{C_{8} H_{18}} p_{O_{2}}$

Fenomena perpindahan massa dan neraca energi di RFR disimulasikan berdasarkan model reaksi heterogen di reaktor unggun 
tetap satu dimensi, yang dioperasikan secara dinamik dengan elemen volume $\Delta V=A_{c} \cdot \Delta z=$ $2 \pi r^{2} \Delta z$, seperti terlihat pada Gambar 3 . Model reaksi heterogen melibatkan dua buah persamaan neraca massa dan neraca energi, masing-masing untuk fasa gas dan fasa katalis. Akan tetapi, fenomena perpindahan massa dalam penelitian ini dimodelkan secara pseudo-homogeneous. Hal ini didasarkan pada asumsi bahwa tidak terjadi hambatan perpindahan massa, sehingga untuk neraca massa hanya melibatkan satu buah persamaan saja. Sedangkan persamaan neraca energi tetap melibatkan dua buah persamaan untuk fasa gas dan fasa padatan.

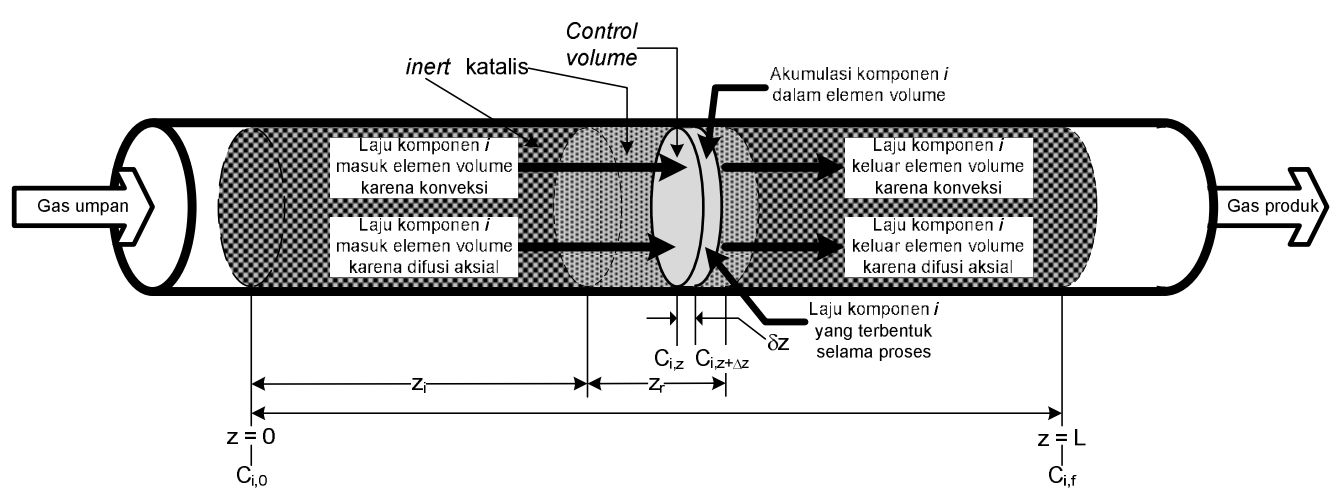

Gambar 3. Skema elemen volume dari reaktor unggun tetap

Tabel 2. Model persamaan neraca massa dan neraca energi reaksi oksidasi katalitik uap bensin

\begin{tabular}{|c|}
\hline $\begin{array}{l}\text { Neraca massa dan energi: } \begin{array}{c}\frac{\partial C_{i}}{\partial t}=-U_{(t)} \frac{\partial C_{i}}{\partial z}+D_{e f f} \frac{\partial^{2} C_{i}}{\partial z^{2}}+R_{\left(x, T_{s}\right)} \\
\epsilon \rho_{g} c_{g} \frac{\partial T_{g}}{\partial t}=-U_{(t)} \rho_{g}^{0} c_{g} \frac{\partial T_{g}}{\partial z}-\alpha_{0} a_{v}\left(T_{g}-T_{s}\right) \\
{\left[(1-\epsilon) \epsilon_{p} \rho_{s} c_{s}+\epsilon_{g} \rho_{g} c_{g}\right] \frac{\partial T_{s}}{\partial t}=\alpha_{0} a_{v}\left(T_{g}-T_{s}\right)+(-\Delta H) R_{\left(x, T_{s}\right)}+k_{e f f} \frac{\partial^{2} T_{s}}{\partial x^{2}}} \\
U_{(t)}=\mathrm{K}_{(t)} u \quad[\mathrm{~K} \text { bernilai }(+1) \text { untuk arah kanan dan }(-1) \text { untuk arah ke kiri }]\end{array}\end{array}$ \\
\hline $\begin{array}{l}C_{i}=C_{i, \text { input }} \\
\text { Kondisi awal: } \\
\qquad T_{g}=303 \mathrm{~K}, \quad T_{s, \text { inert }}=773 \mathrm{~K}, \quad T_{s, \text { katalis }}=773 \mathrm{~K} \\
\end{array}$ \\
\hline Kondisi batas: $\begin{aligned} C_{i}=C_{i, \text { input }}, T_{g}= & T_{\text {g,input }} \text { dan } \frac{\partial \mathrm{T}_{\mathrm{s}}}{\partial z}=0 \text { pada } z=0 \\
& \frac{\partial C_{i}}{\partial z}=0, \frac{\partial T_{s}}{\partial z}=0 \text { pada } z=L\end{aligned}$ \\
\hline $\begin{array}{c}\text { Catatan: Deskripsi dari masing - masing notasi dapat dilihat di Daftar Notasi } \\
\text { Tabel 3. Dimensi reaktor }\end{array}$ \\
\hline Diameter reactor $\left(D_{T}\right)$ \\
\hline Panjang total reactor $\left(L_{r}\right)$ \\
\hline Stainless Steel SS 304 L \\
\hline $\begin{array}{l}\text { Zona inert } \\
\quad \text { Panjang per segmen inert }\left(z_{i}\right) \\
\text { Material unggun inert } \\
\text { Diameter rata-rata partikel unggun }\end{array}$ \\
\hline $\begin{array}{l}\text { Zona katalis } \\
\text { Panjang zona katalis }\left(z_{r}\right) \\
\text { Material unggun katalis } \\
\text { Diameter rata-rata partikel unggun }\end{array}$ \\
\hline
\end{tabular}


Tabel 4. Kondisi operasi, parameter kinetika reaksi dan sifat-sifat fisik untuk simulasi reaksi oksidasi uap bensin dalam RFR

\begin{tabular}{lccc}
\hline & Simbol & Nilai & Satuan \\
\hline Reaksi : & & & \\
$\mathrm{C}_{8} \mathrm{H}_{18}+121 / 2 \mathrm{O}_{2} \rightarrow 8 \mathrm{CO}_{2}+9 \mathrm{H}_{2} \mathrm{O}$ & $k_{0, C_{8} \mathrm{H}_{18}}$ & $2,58 \cdot 10^{8}$ & mol.gkatalis ${ }^{-1} \cdot \mathrm{detik}^{-1} \cdot \mathrm{bar}^{-2}$ \\
Sumber: [Petrachi dkk., 2005] & $E a_{C_{8} H_{18}}$ & 166 & $\mathrm{kj} \cdot \mathrm{mol}^{-1}$ \\
& $\Delta H_{r, C_{8} H_{18}}$ & $-5100,5$ & $\mathrm{~kJ} \cdot \mathrm{mol}^{-1}$ \\
\hline Material inert : & & & \\
Dolomit & $c_{s}$ & 0,920 & $\mathrm{~kJ} \cdot \mathrm{kg}^{-1} \cdot \mathrm{K}^{-1}$ \\
Sumber: [Marin dkk., 2008] & $K$ & 5,51 & $\mathrm{~W} \cdot \mathrm{m}^{-1} \cdot \mathrm{K}^{-1}$ \\
& $\rho$ & 2800 & $\mathrm{~kg} \cdot \mathrm{m}^{-3}$ \\
& $d_{p}$ & 0,002 & $\mathrm{Mm}$ \\
\hline Material katalis : & & & \\
Pt $/ \gamma-\mathrm{Al}_{2} \mathrm{O}_{3}$ & $c_{s}$ & 0,836 & $\mathrm{~kJ} \cdot \mathrm{kg}^{-1} \cdot \mathrm{K}^{-1}$ \\
Sumber: [Marin dkk., 2008] & $K$ & 0.042 & $\mathrm{~W} \cdot \mathrm{m}^{-1} \cdot \mathrm{K}^{-1}$ \\
& $\rho$ & 1541 & $\mathrm{~kg} \cdot \mathrm{m}^{-3}$ \\
& $d_{p}$ & 0,0023 & $\mathrm{Mm}$ \\
\hline
\end{tabular}

Catatan: Deskripsi dari masing - masing notasi dapat dilihat di Daftar Notasi

Persamaan neraca massa dan neraca energi reaksi oksidasi uap bensin di RFR yang digunakan dalam kajian ini, secara lengkap dapat dilihat di Tabel 2. Dimensi reaktor secara lengkap dapat dilihat di Tabel 3 , sedangkan kondisi operasi, parameter kinetika reaksi, dan sifat-sifat fisik yang digunakan dalam menyelesaikan model dapat dilihat di Tabel 4.

\section{Simulasi}

Simulasi diawali dengan operasi RFR satu arah. Simulasi dilakukan untuk mengetahui kestabilan reaksi oksidasi uap bensin. Hasil simulasi reaksi oksidasi di RFR dengan mode operasi satu arah (one way operation) digunakan sebagai dasar penentuan kondisi operasi dengan mode operasi bolak-balik (reverse flow operation = RFO). Setelah kondisi operasi satu arah dijalankan, simulasi RFO dilakukan dengan metoda start-up tertentu. Pemilihan metoda start-up untuk RFO merupakan bagian yang penting dalam pengoperasian reaksi oksidasi uap bensin dalam RFR. Metoda yang dipilih harus dapat menjamin agar RFR berlaku sebagai reaktor ototermal, sehingga reaksi oksidasi katalitik uap bensin dapat berlangsung tanpa bantuan prehetaer. Metoda start-up yang akan digunakan dalam kajian ini adalah seluruh unggun reaktor (inert dan katalis) dipanaskan hingga mencapai temperatur di atas temperatur ignition (pembakaran) uap bensin, sehingga uap bensin akan segera bereaksi ketika memasuki zona katalis. Temperatur yang digunakan, dipilih seminimal mungkin di atas temperatur pembakaran uap bensin, yaitu 773 K. Gas umpan dialirkan ke dalam reaktor pada kondisi dingin, dengan temperatur yang sama dengan temperatur udara.

\section{Hasil dan Pembahasan}

Oksidasi katalitik banyak digunakan dalam upaya pengurangan VOC karena membutuhkan suhu pembakaran yang lebih rendah daripada proses pengurangan VOC melalui pembakaran termal homogen (homogeneous thermal combustion). Akan tetapi, suhu reaksi pembakaran tersebut harus melampaui suhu pembakaran (auto ignition temperature) dari komponen yang terdapat di dalam reaktor. Suhu pembakaran iso-oktana adalah $427^{\circ} \mathrm{C}(690$ $\mathrm{K}$, sehingga reaksi oksidasi katalitik diselenggarakan di atas suhu tersebut.

\section{Operasi satu arah (one way operation)}

Simulasi reaksi oksidasi dalam RFR mode operasi satu arah dilakukan pada suhu $773 \mathrm{~K}$. Unggun yang terdapat dalam reaktor dipanaskan dengan cara mengalirkan udara panas ke dalam reaktor selama rentang waktu tertentu. Setelah suhu reaktor seragam, maka umpan yang berada dalam suhu kamar (303 K) dialirkan ke dalam reaktor. Selama proses berlangsung, reaktor berada dalam kondisi adiabatis, tidak ada panas yang diambil maupun ditambahkan ke 

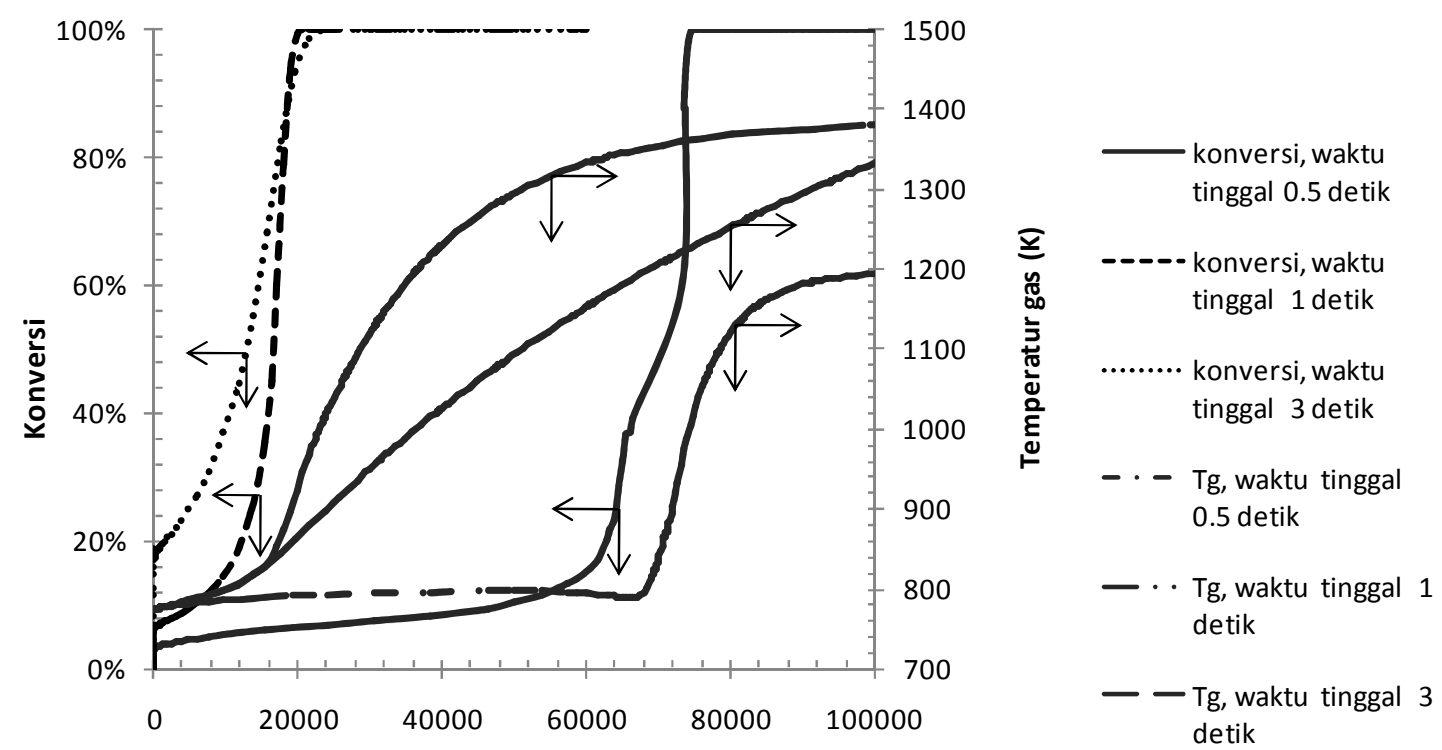

Waktu (detik)

Gambar 4. Profil temperatur gas dan konversi reaksi sepanjang waktu, operasi satu arah / one way operation (variasi waktu tinggal).

dalam sistem. Hasil simulasi operasi satu arah ditunjukkan dalam Gambar 4. Dari gambar tersebut terlihat bahwa uap bensin dapat terkonversi sempurna (konversi mencapai 100\%). Waktu tinggal yang rendah $(0,5$ detik $)$ membutuhkan waktu yang lebih lama untuk mencapai konversi 100\%. Cittadini dkk. (2001) menyatakan bahwa kondisi ototermal untuk RFO dengan konsentrasi umpan yang rendah hanya bisa dicapai apabila umpan terkonversi 100\%. Dengan demikian, reaksi oksidasi uap bensin di RFR memungkinkan untuk berjalan secara ototermal.

Gambar 4 juga menampilkan profil temperatur gas selama berlangsungnya proses oksidasi. Temperatur saat kondisi operasi satu arah semakin tinggi dengan bertambahnya waktu tinggal. Temperatur yang tinggi ini menunjukkan adanya akumulasi panas di dalam unggun selama berlangsungnya proses oksidasi. Dalam operasi bolak-balik (reverse flow operation RFO), akumulasi panas tersebut akan dimanfaatkan untuk memanaskan umpan. Semakin besar panas yang terakumulasi maka kondisi ototermal lebih mudah tercapai. Akan tetapi kemampuan alat menjadi batasan, sehingga temperatur di dalam reaktor harus dijaga agar tidak melewati batas kemampuan alat. RFR dibuat dari stainless steel yang dapat dioperasikan hingga mencapai suhu $870-950{ }^{\circ} \mathrm{C}(1143 \mathrm{~K}$ $1223 \mathrm{~K}$ ) [Schweitzer, 2003].

\section{Operasi Bolak-balik (reverse flow operation - RF0)}

Untuk reaksi yang tidak dapat balik (irreversible reaction), seperti oksidasi VOC, penggunaan reaktor dinamik dapat meningkatkan nilai efisiensi termal sistem. Nilai efisiensi termal yang tinggi ini memberikan beberapa keuntungan, yaitu (1) reaktor dapat berjalan ototermal meskipun konsentrasi gas umpan kecil, (2) temperatur maksimum dalam reaktor dapat lebih mudah dikendalikan, khususnya apabila konsentrasi gas umpan cukup besar, dan (3) reaktor mampu mengakomodasi perubahan konsentrasi umpan maupun laju umpan [Cittadini dkk., 1999].

Reaksi oksidasi uap bensin merupakan salah satu reaksi eksotermis dengan panas reaksi yang besar yaitu $\Delta H_{r}=$ $-5.100,5 \mathrm{~kJ} / \mathrm{mol}$ ). Hasil simulasi reaksi oksidasi uap bensin operasi satu arah (Gambar 4) juga menunjukkan bahwa reaksi oksidasi uap bensin menghasilkan temperatur yang cukup tinggi. Dengan demikian, penggunaan RFR diharapkan dapat mengendalikan temperatur maksimum di dalam reaktor selama berlangsungnya reaksi, sekaligus dapat memanfaatkan panas yang terakumulasi. 
Untuk mengetahui dinamika reaktor dinamik, maka simulasi reaksi oksidasi uap bensin aliran bolak-balik (RFO) perlu dilakukan. Simulasi RFO dilakukan dengan kondisi operasi yang sama dengan kondisi operasi satu arah, dan waktu tinggal yang dipilih adalah 1 detik. Hal ini didasarkan kecepatan untuk mencapai konversi reaksi $100 \%$ dan temperatur di unggun yang tidak terlalu tinggi.

Gambar 5 menunjukkan profil temperatur sepanjang reaktor selama berlangsungnya proses start-up reaksi oksidasi uap bensin kondisi RFO dibanding kondisi operasi satu arah. Kondisi RFO menyebabkan temperatur di dalam reaktor, baik temperatur gas maupun temperatur fasa padat, lebih tinggi daripada kondisi operasi satu arah. Dengan adanya perubahan arah aliran selama selang waktu tertentu maka panas hasil reaksi terjebak di dalam unggun inert. Panas yang terjebak ini menyebabkan RFR dianggap sebagai regenerative heat exchanger [Barresi dkk., 2007].

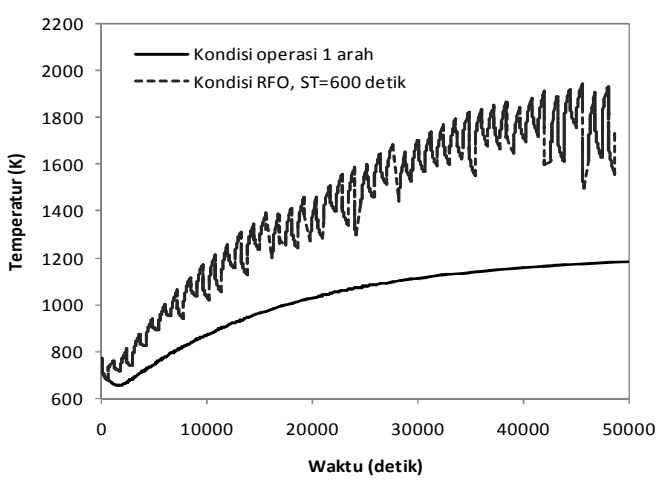

(a)
Gambar 5 juga menunjukkan hasil simulasi kondisi RFO dengan selang waktu perubahan aliran (switching time $=S T$ ) 600 detik. Switching time sangat mempengaruhi kelakuan dinamik RFR. Penggunaan switching time yang terlalu kecil atau terlalu besar dapat menyebabkan unggun reaktor, khususnya sisi katalis, mengalami pemanasan yang berlebihan [Marin dkk., 2009]. Kondisi ini harus dihindari karena dapat menyebabkan deaktivasi katalis maupun kerusakan alat. Dengan demikian pengambilan panas perlu dilakukan. Dalam kajian ini, pengambilan panas hanya dilakukan di zona katalis, dengan laju pengambilan panas yang tetap, yaitu sebesar $500 \mathrm{~kJ} / \mathrm{m}^{3}$.detik. Pengambilan panas dilakukan secara otomatis ketika temperatur katalis mencapai $1000 \mathrm{~K}$. Hasil simulasi kondisi RFO, ST 600 detik, tanpa pengambilan panas dan dengan pengambilan panas dapat dilihat di Gambar 6.

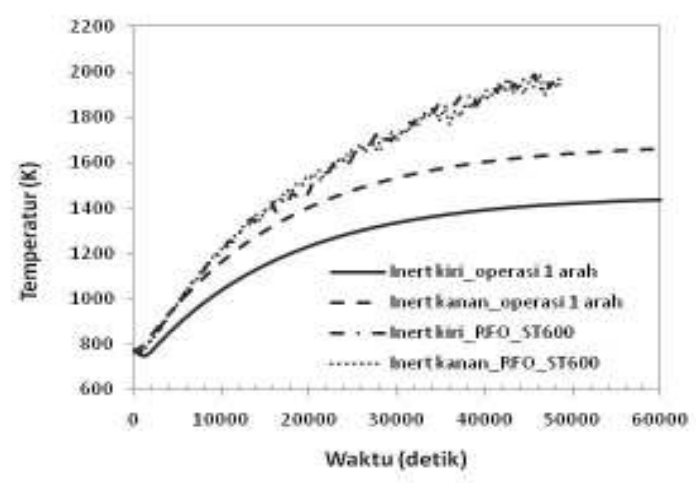

(b)

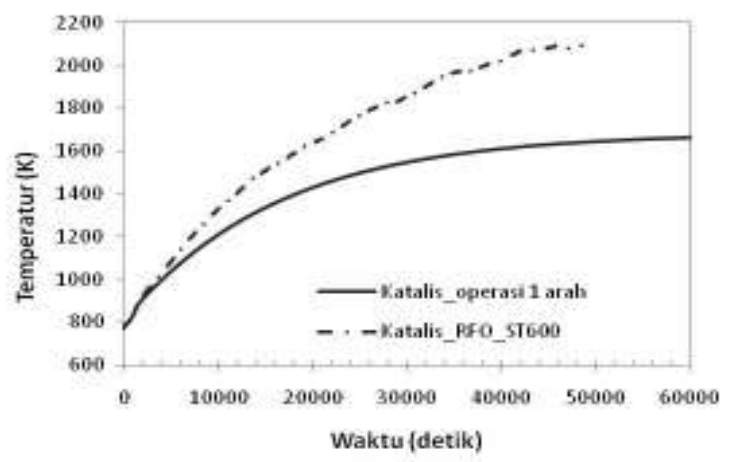

(c)

Gambar 5. Profil temperatur gas (a), temperatur inert (b), dan temperatur katalis (c) kondisi operasi satu arah dan kondisi RFO - switching time (ST) 600 detik. 


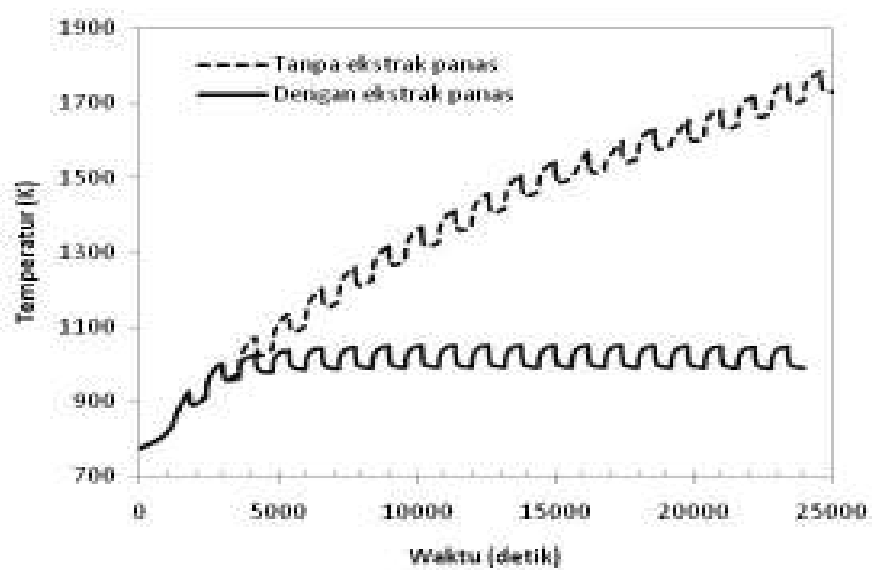

Gambar 6. Perbandingan profil temperatur reaktor RFO - ST 600 detik, dengan pengambilan panas dan tanpa pengambilan panas.

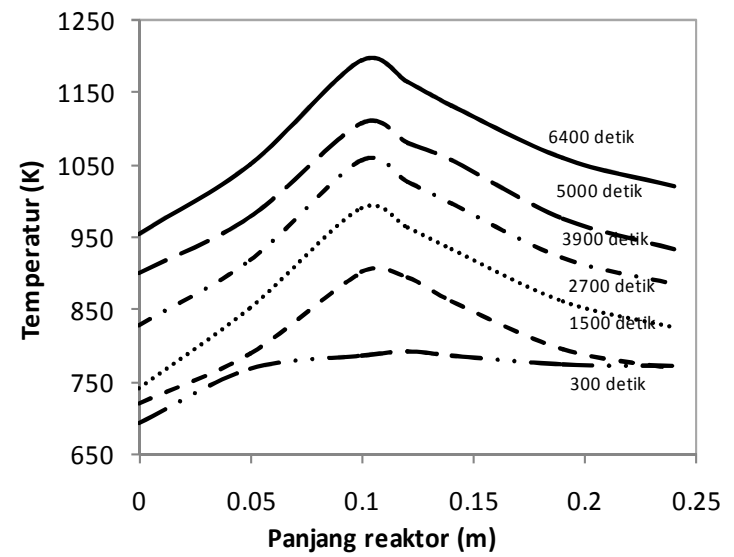

(a)

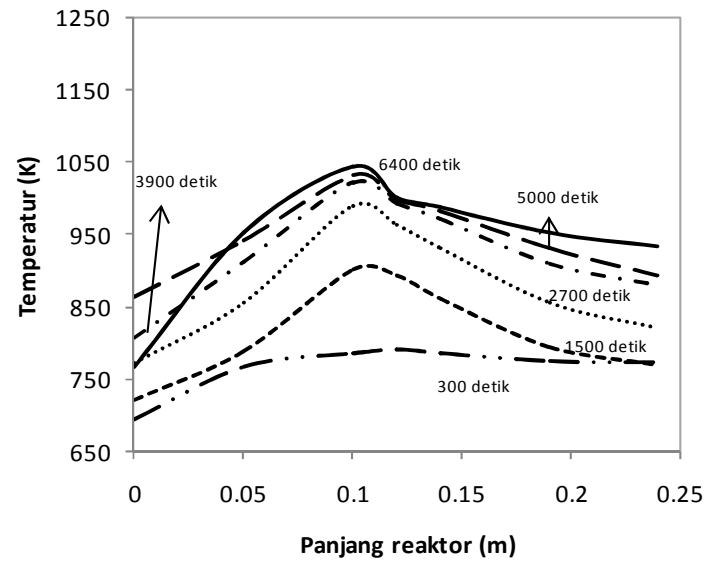

(b)

Gambar 7. Perubahan profil temperatur sepanjang reaktor pada berbagai $t$, tanpa pengambilan panas (a) dan perubahan profil temperatur sepanjang reaktor pada berbagai $t$ dengan pengambilan panas (b).

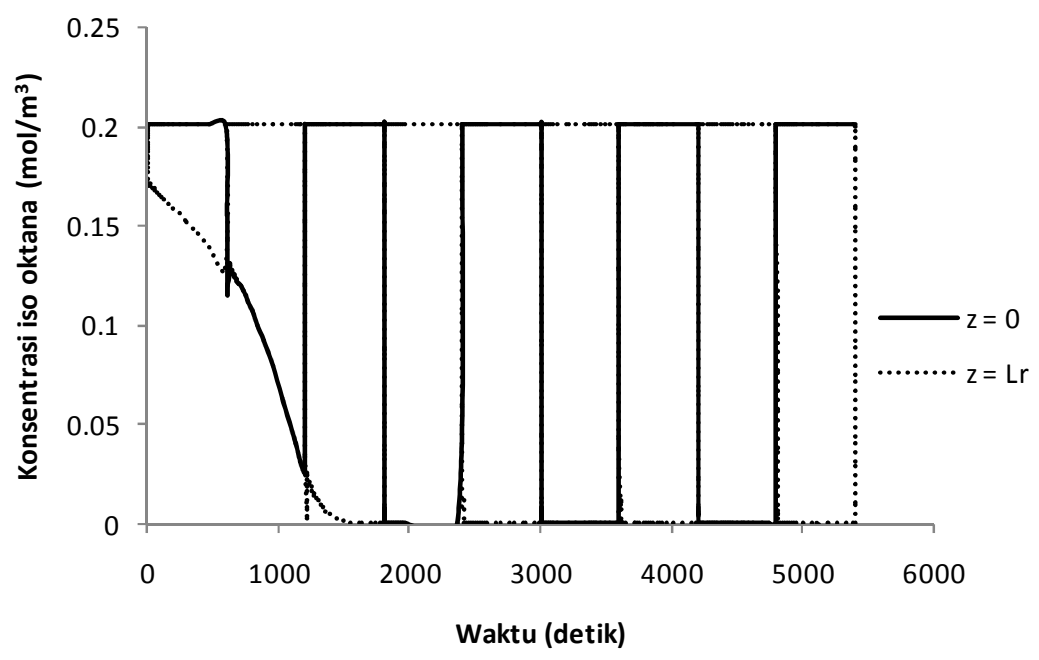

Gambar 8. Profil konsentrasi iso-oktana kondisi RFO - ST 600 detik 
Jika pengambilan panas tidak dilakukan maka ada kemungkinan terjadi kenaikan temperatur yang tinggi di unggun reaktor. Fenomena ini dikenal dengan istilah "runaway" dan harus dihindari karena dapat membahayakan reaktor. Sebaliknya, jika panas dari reaktor diambil secara periodik, maka temperatur reaktor akan berfluktuasi secara periodik dan reaktor berkelakuan dinamik yang lebih stabil. Pengambilan panas yang dilakukan menjaga agar temperatur reaktor tidak lebih dari $1000 \mathrm{~K}$, sehingga deaktivasi katalis dan kerusakan alat dapat dihindari. Perubahan profil temperatur sepanjang reaktor, dari waktu ke waktu, untuk RFO tanpa pengambilan panas dan dengan pengambilan panas dapat dilihat di Gambar 7(a) dan 7(b). Dengan adanya pengambilan panas, temperatur maksimum di unggun reaktor dapat dikendalikan. Panas yang diambil selama proses RFO berlangsung tidak menyebabkan proses terganggu, bahkan kondisi pseudo steady state lebih cepat tercapai. Akumulasi panas tersebut dapat dimanfaatkan lebih lanjut, di antaranya untuk memanaskan umpan maupun unggun reaktor di awal proses (saat start-up).

Capaian konversi reaksi untuk kondisi RFO dapat dilihat di Gambar 8. Dari gambar tersebut terlihat bahwa reaksi akan mencapai konversi $100 \%$ setelah 1500 detik. Waktu untuk mencapai konversi $100 \%$ ini jauh lebih cepat apabila dibandingkan dengan operasi satu arah. Operasi satu arah, seperti terlihat di Gambar 4, menunjukkan bahwa waktu yang dibutuhkan untuk mencapai konversi $100 \%$, dengan waktu tinggal 1 detik, adalah 16000 detik.

\section{Kesimpulan}

Reaksi oksidasi katalitik uap bensin yang diselenggarakan dalam reverse flow reactor (RFR) telah dimodelkan dan disimulasikan menggunakan perangkat lunak FlexPDE versi 6.0 (PDE Solutions Inc., 2009). Simulasi berjalan dengan baik untuk mode operasi satu arah (one way operation) maupun mode operasi bolak - balik (reverse flow operation - RFO). Uap bensin dapat terkonversi dengan sempurna untuk semua mode operasi.

Reaksi oksidasi katalitik uap bensin yang diselenggarakan dengan mode operasi RFO menyebabkan temperatur di dalam reaktor, baik temperatur gas maupun temperatur fasa padat, lebih tinggi daripada kondisi operasi satu arah. Hal ini terjadi karena panas hasil reaksi terjebak di dalam unggun reaktor sebagai akibat adanya perubahan arah aliran selama selang waktu tertentu. Panas yang terakumulasi di unggun reaktor tersebut dapat dimanfaatkan dalam proses start-up untuk memanaskan gas umpan maupun untuk memanaskan unggun itu sendiri. Selain itu, mode operasi RFO juga mempercepat tercapainya konversi $100 \%$.

\section{DAFTAR NOTASI}

\begin{tabular}{|c|c|}
\hline Simbol & Keterangan \\
\hline$a_{v}$ & $\begin{array}{l}\text { luas permukaan spesifik katalis, } \\
\mathrm{m}^{2} / \mathrm{m}^{3}\end{array}$ \\
\hline$c_{g}$ & kapasitas panas gas, kJ/kg.K \\
\hline$c_{S}$ & kapasitas panas katalis, \\
\hline$C_{i}$ & $\begin{array}{l}\text { konsentrasi komponen } \\
\mathrm{mol} / \mathrm{m}^{3}\end{array}$ \\
\hline$d_{p}$ & diameter efektif partikel, m \\
\hline$D_{T}$ & diameter reaktor, $\mathrm{m}$ \\
\hline$E_{a}$ & energi aktivasi, kJ/mol \\
\hline$k_{C 8 H 18}$ & $\begin{array}{l}\text { konstanta kecepatan reaksi iso- } \\
\text { oktana dengan hidroksil radikal } \\
{\left[\mathrm{OH}^{-}\right], \mathrm{cm}^{3} / \text { molekul.detik }}\end{array}$ \\
\hline$K$ & konduktivitas termal, W/m.K \\
\hline$L_{r}$ & panjang reaktor, $\mathrm{m}$ \\
\hline$r_{A}$ & $\begin{array}{l}\text { laju reaksi pembentukan } \mathrm{A} \text {, } \\
\mathrm{kmol} \mathrm{A} / \mathrm{kg} \text { katalis.detik }\end{array}$ \\
\hline$S T$ & switching time, detik \\
\hline$t$ & Waktu, detik \\
\hline$T_{g}$ & temperatur gas, $\mathrm{K}$ \\
\hline$T_{s}$ & $\begin{array}{l}\text { temperatur di permukaan } \\
\text { katalis, } \mathrm{K}\end{array}$ \\
\hline$u$ & $\begin{array}{l}\text { nilai kecepatan linier gas } \\
\text { umpan, m/detik }\end{array}$ \\
\hline$U_{(t)}$ & kecepatan gas umpan, m/detik \\
\hline$Z$ & panjang unggun, m \\
\hline $\mathrm{K}_{(t)}$ & vektor penunjuk arah aliran \\
\hline$\alpha_{0}$ & $\begin{array}{l}\text { koefisien perpindahan panas, } \\
\mathrm{J} / \mathrm{m}^{2} \text {.K.detik }\end{array}$ \\
\hline$\Delta H_{r}$ & panas reaksi, kJ/mol \\
\hline$\Delta T_{a d}$ & $\begin{array}{l}\text { kenaikan temperatur umpan } \\
\text { pada reaktor yang beroperasi } \\
\text { secara adiabatik, } \mathrm{K}\end{array}$ \\
\hline$\Delta T_{p}$ & $\begin{array}{l}\text { kenaikan temperatur yang } \\
\text { dibutuhkan untuk membawa } \\
\text { umpan menuju ke kondisi } \\
\text { temperatur optimum reaktor, } \mathrm{K}\end{array}$ \\
\hline$\epsilon$ & $\begin{array}{l}\text { fraksi ruang kosong dalam bed, } \\
\text { tidak berdimensi }\end{array}$ \\
\hline$\epsilon_{g}$ & $\begin{array}{l}\text { fraksi gas dalam bed, tidak } \\
\text { berdimensi }\end{array}$ \\
\hline$\epsilon_{p}$ & fraksi ruang kosong dalam \\
\hline
\end{tabular}




\begin{tabular}{ll}
\hline & \multicolumn{2}{l}{ partikel, tidak berdimensi } \\
$\eta$ & $\begin{array}{l}\text { efisiensi dari proses } \\
\text { pengambilan panas, } \%\end{array}$ \\
& densitas fluida, $\mathrm{kg} / \mathrm{m}^{3}$ \\
$\rho$ & densitas gas, $\mathrm{kg} / \mathrm{m}^{3}$ \\
$\rho_{g}$ & densitas gas pada saat $t=0$, \\
$\rho_{g}^{0}$ & $\mathrm{~kg} / \mathrm{m}^{3}$ \\
\hline
\end{tabular}

\section{Daftar Pustaka}

Allen, D.T.; Shonnard, D.R., Green Engineering: environmentally conscious design of chemical processes, Prentice Hall, 2002.

Barresi, A.A.; Baldi, G.; Fissore, D., Forced Unsteady-State Reactors as Efficient Devices for Integrated Processes: Case Histories and New Perspectives, Industrial \& Engineering Chemistry Research, 2007, Vol. 46(25), 8693-8700.

Budhi, Y.W., Reverse Flow Reactor Operation for Control of Catalyst Surface Coverage, Proefschrift (Disertasi), Technische Universiteit Eindhoven, Eindhoven, 2005.

Chameides, W.L.; Amann, C.A.; Atkinson, R.; Ozone-forming potential of reformulated gasoline compass series, National Academies Press, 1999.

Cittadini, M.; Vanni, M.; Barresi, A.A.; Baldi, G., Efficient design and scale-up of reversefow catalytic combustors, AIDIC conference series, 4, 131-138, 1999.

Cittadini, M., Vanni, M., Barresi, A.A., dan Baldi, G., Reverse-flow catalytic burners: response to periodical variations in the feed, Chemical Engineering Science, 2001, Vol. 56(4), 1443 - 1449.

Erwin, Pengembangan Prototipe Vent Processor pada Vapor Recovery System di SPBU Menggunakan Teknologi Membran, Skripsi Program Sarjana, Program Studi
Teknik Mesin, Institut Teknologi Bandung, 2007.

Matros, Y.S.; Bunimovich, G.A., Reverse-Flow Operation in Fixed Bed Catalytic Reactors, Catalyst Reviews Science and Engineering, 1996, Vol. 38(1), 1-68.

Marin, P.; Ordóñez, S.; Díez, F.V., Combustion of toluene-hexane binary mixtures in a reverse flow catalytic reactor, Chemical Engineering Science, 2008, Vol. 63(20), 5003-5009.

Marin, P.; Ordóñez, S.; Díez, F.V., Systematic study of the performance of a reverse flow reactor for the treatment of lean hydrocarbon emissions, Journal of Chemical Technology and Biotechnology, 2009, Vol. 84(9), 12921302.

Petrachi, G.A.; Negro, G.; Specchia, S.; Saracco, G., Maffettone, P.I.; Specchia, V., Combining Catalytic Combustion and Steam Reforming in a Novel Multifunctional Reactor for On-Board Hydrogen Production from Middle Distillates, Industrial \& Engineering Chemistry Research, 2005, Vol. 44(25), 9422-9430.

Reshetnikov, S.I.; Ivanov, E.A.; Kiwi-Minsker, L.; Renken, A., Performance enhancement by unsteady-state reactor operation: Theoretical analysis for two-sites kinetic model, Chemical Engineering \& Technology, 2003, Vol. 26(7), 751-758.

Schweitzer, P.A., Metallic Materials; Physical, Mechanical, and Corrosion Properties, Marcel Dekker, Inc., New York, 2003.

Silveston, P.; Hudgins, R.R.; Renken, A., Periodic operation of catalytic reactors introduction and overview, Catalysis Today, 1995, Vol 25(2), 91 - 112.

Silveston, P.L., Composition Modulation of Catalytic Reactors, Gordon and Breach Science, Ontario, 1998. 